Pure Appl. Chem., Vol. 85, No. 9, pp. 1771-1787, 2013.

http://dx.doi.org/10.1351/PAC-CON-12-11-14

(C) 2013 IUPAC, Publication date (Web): 22 July 2013

\title{
NMR studies on carbohydrate interactions with DC-SIGN towards a quantitative STD analysis*
}

\author{
Cinzia Guzzi, Juan Carlos Muñoz-García, Pedro M. Enriquez-Navas, \\ Javier Rojo, Jesús Angulo, and Pedro M. Nieto $¥$ \\ Glycosystems Laboratory, Department of Bioorganic Chemistry, Instituto de \\ Investigaciones Químicas (CSIC), Avda. Américo Vespucio 49, Sevilla 41092, \\ Spain
}

\begin{abstract}
The recent introduction of saturation transfer difference (STD) NMR has increased the tools for the study of protein-carbohydrate complexes. This is useful when it is combined with transfer nuclear Overhauser enhancement spectroscopy (NOESY) measurement, or when it is interpreted using the expected calculated values of transference, yielding additional, very valuable information for the study of this type of complex.

The objective of this work is to cover the advances of the STD technique as exemplified by the investigations of DC-SIGN (dendritic cell-specific ICAM-3 grabbing non-integrin) recognition by simple carbohydrates or mimics of them, based on structures containing a terminal mannose or fucose. We also will discuss the methods for quantification of the STD values based on the initial growing rates with the saturation time.
\end{abstract}

Keywords: carbohydrates; lectin; molecular interactions; molecular recognition; NMR.

\section{INTRODUCTION}

Dendritic cells (DCs) are key players in the initial response to pathogens as they are the first participants in the long series of events in host-pathogen interaction leading to activation of specific $\mathrm{T}$ cells $[1,2]$. They are found in epidermal and mucosal tissues and are thus able to quickly recognize new invading pathogens through the identification of pathogen-associated molecular patterns (PAMPs). Apart from the Toll-like receptor family of pattern recognition receptors (PRRs), they also possess C-type lectin receptors (CLRs) dedicated to the specific recognition of pathogen carbohydrate patterns [3]. Among these CLRs, DC-SIGN (dendritic cell-specific ICAM-3 grabbing non-integrin) has attracted a great deal of attention during the past decade. Initially highlighted for its role in HIV transmission to T cells [4], it has then been identified as a PRR hijacked by many other pathogens (e.g., some viruses, bacteria, fungi, and parasites) to escape immune response in their infectious processes $[5,6]$. More recently, DC-SIGN has also been found to be involved in the modulation of the immune response [7].

DC-SIGN is a type II transmembrane protein with a short cytosolic region, a transmembrane segment, and an extended extracellular domain (ECD) ending in a carbohydrate recognition domain (CRD) located at $320 \AA$ above the cell surface to interact with potential antigens [8]. This ECD is divided into two regions: a neck region, involved in the tetramerization of the receptor constituted by seven and a

*Pure Appl. Chem. 85, 1759-1900 (2013). A collection of invited papers based on presentations at the $26^{\text {th }}$ International Carbohydrate Symposium (ICS 2012), Madrid, Spain, 22-27 July 2012.

¥Corresponding author: E-mail: pedro.nieto@iiq.csic.es 
half repeating units, and a calcium-dependent CRD, which is responsible for the molecular recognition processes mediated by DC-SIGN [8].

In recent years, many strategies have arisen to block DC-SIGN CRD avoiding its use by pathogen glycoproteins [9-12]. Natural ligands are frequently recognized by DC-SIGN in a multimodal fashion by using not only its tetrameric state but also taking advantage of its organization into clustered patches at the cell membrane $[13,14]$.

Several efforts have been made to apply a multiple ligand presentation platform (polymers, dendrimers, or nanoparticles) [15-18]. We initially demonstrated that dendrimers loaded with multiple copies of mannose were able to inhibit DC-SIGN/gp120 interaction [9]. However, mannose, as a natural ligand, is not specific enough for in vivo practical applications. The design of a ligand with good selectivity and basal affinity is of essential importance. We have been designing new synthetic molecules mimicking natural sugar properties, and we have studied the natural ligands in order to understand the recognition process to improve the characteristics of the ligand [19-22]. In this sense, we have been studying by NMR and saturation transfer difference (STD) the interaction between the monomeric natural ligands and/or the mimetics, and these studies are going to be reviewed here.

\section{BASIS OF STD}

Transference of saturation in transient complexes has been studied since the early 1960s [23,24], but in its present form, STD NMR, was proposed in 1999 by Mayer as a screening technique allowing the detection of the saturation acquired by the free ligand from the complex in the averaged signals in fast exchange dominated by the free ligand [25]. Since then, STD NMR has become a very versatile and robust ligand-observed NMR technique, with growing applications extending its applicability [26-29].

The STD NMR experiment relays in the difference between a 1D NMR experiment in which the receptor is selectively saturated by a low-power radio frequency (on-resonance experiment). In case of binding, the saturation acquired by the ligand signal would be detected by an increase of the corresponding signal in the difference experiment where a reference experiment (off-resonance) is subtracted by the on-resonance. The saturation, which is responsible for the difference between the signals, is accumulated in solution and its magnitude, firstly proportional to the saturation time, is carrying information about the binding constant and kinetics, geometry, and stoichiometry of the complex. Although the experiment is basically the same, the conditions, parameters, and modes of processing can be adjusted according to the application. In addition, a number of new implementations have been described, once the magnetization is transferred to the ligand it can be manipulated by hyphenated experiments [30,31] or by heteronuclear editing [32,33], extending its applications.

The primary magnitude obtained from the STD experiment is the absolute STD value numerically expressed as a percentage of the NMR signal relative to the non-saturating spectrum $[100 \times$

$\left(I_{\text {off-resonance }}-I_{\text {on-resonance }}\right) / I_{\text {off-resonance }}$. The value can be reprocessed to obtain the relative $S T D$ to perform an epitope-mapping analysis by scaling to $100 \%$ relative to the most intense absolute STD signal [30]. If the first one can be interpreted in terms of the existence of transient binding and is useful in the case of library screening [27], the second one has been used to map the interaction epitope, which in principle is dependent on the number and distances of saturated spins of the protein close to each ligand proton in the complex in a dipolar interaction fashion inversely proportional to the sixth power of the distance. Another STD-derived magnitude is the STD amplification factor (STD-AF) corresponding to the percentage of relative $S T D$ multiplied by the ligand excess over the receptor [30]. Additionally, the initial growth rate of the STD $\left(S T D_{0}\right)$ can be measured by fitting the curve to a monoexponential equation (see below) [34]. 


\section{STD for epitope mapping}

\section{Mannose di- and trisaccharides from gp-120}

gp-120 is a heavily glycosylated protein that is found on the surface of the HIV envelope and is responsible for the first events that lead to viral entry into the cells and to further infection [35]. This process is mediated by the interaction of the glycan part of the gp120, from the virus envelope, with DC-SIGN. The process is mediated by the interaction of some sugars with $\mathrm{Ca}^{2+}$ atom, which is present in the binding site of this lectin. This occurs via the coordination with two adjacent hydroxyl groups from mannose- or fucose-type sugar residues [36].

We start the studies by comparing two branched natural trisaccharides inspired by those enclosed in some mannose-containing natural structures (Man $\alpha(1-2)[\operatorname{Man} \alpha(1-6)] \operatorname{Man}, \mathbf{1}$, and Man $\alpha(1-$ 3)[Man $\alpha(1-6)]$ Man, 2). Basically, the differences are that the first one is included in the high-mannose $\left(\mathrm{Man}_{9} \mathrm{GlcNAc}_{2}\right)$ structures found in the HIV envelope, while the second one constitutes the repeating unit of the cell-wall lipoarabinomannans, which is also recognized by DC-SIGN. The NMR study was performed recording NOESY experiments in the absence and presence of DC-SIGN EDC (ensuring that DC-SIGN is a tetrameric aggregate), as well as STD NMR experiments for epitope mapping (Fig. 1) [37].

The transfer NOESY experiments [38-40] (Fig. 1) indicate that in those conditions there is binding to CD-SIGN EDC from $\mathbf{1}$ and $\mathbf{2}$ as deduced from the change in sign of the NOE cross-peaks, relative to the free experiments. In spite of the apparent differences between the NOESY experiments of the trimannosides alone and in the presence of DC-SIGN, those are due to the changes in the correlation time, which allows for larger spin diffusion, and are consistent with the same conformation in the bound and free state. The STD at $2.5 \mathrm{~s}$ of mixing time data indicated that the larger contact with the receptor is with ring $\mathrm{C}$ for trisaccharide $\mathbf{1}$ and for ring $\mathrm{D}$ for $\mathbf{2}$ [37]. The second ring is the central one in both cases, while the weaker contacts are observed for the 1-6 linked mannose. The results are consistent with a model of binding in which the terminal non-1-6 linked mannose is the ring that is interacting with the $\mathrm{Ca}^{2+}$ atom, and the central sugar is following, while the terminal residue bound between the 1 and 6 positions is far from the main binding site. All these results allowed us to propose a model of interaction in which the interaction with the $\mathrm{Ca}^{2+}$ atom, which is known to be the key point for complex formation, occurs between two hydroxyl groups in the trans diequatorial 3 and 4 positions of the binding mannose, see Fig. 2.

\section{Mannose-containing mimetics}

We have also shown the potential multimodal binding of mannose derivatives to DC-SIGN (see below) $[16,42]$. A series of glycomimetics have been prepared by replacing in the mannose series a non-terminal residue by a cyclohexyl moiety with two amides with additional substituents capable of additional interactions [19]. After the $\alpha$ 1-2 dimannoside scaffold" (or "trimannoside 1 scaffold"), a further series of glycomimetics was prepared by replacing the "reducing end mannose" (or "internal mannose") by a cyclohexyl moiety with two carboxymethyl esters as additional substituents capable of additional interactions [43]. Interestingly, in the case of $\mathbf{3 b}$, the introduction of a triazol moiety had an additional spectroscopic benefit of favoring the dispersion of the cyclohexyl signals in respect to $\mathbf{3 a}$ without modifying the binding mode nor the affinity, thus facilitating a more accurate analysis of the STD data, see Fig. 3. 
A

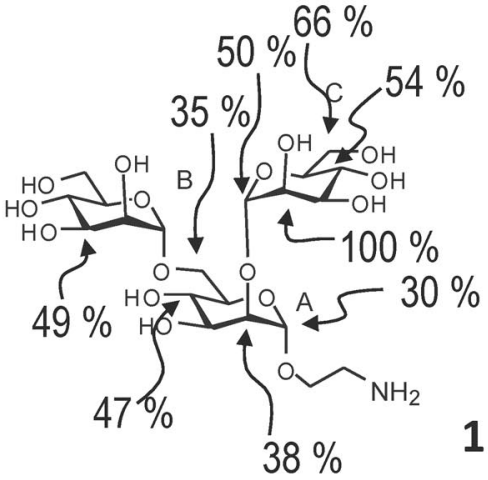

C
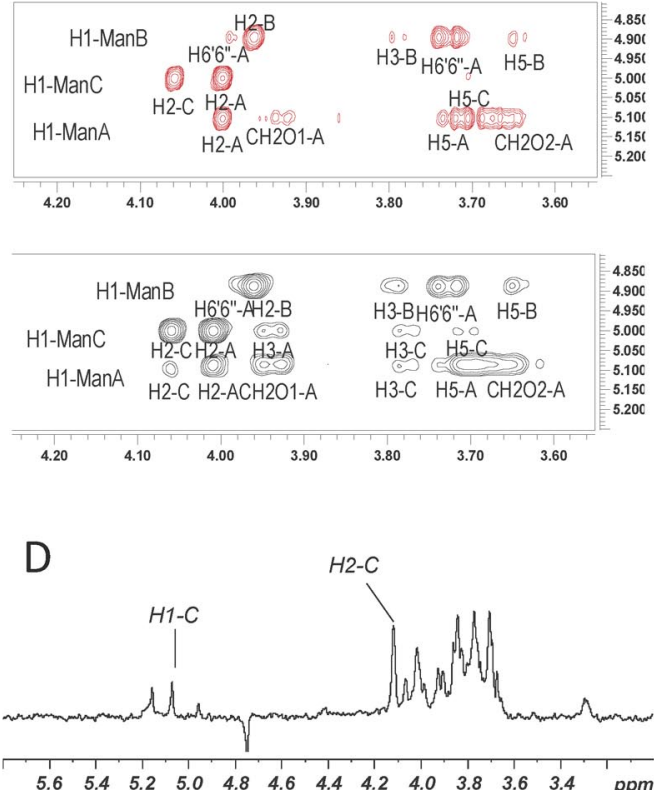

STD spectrum

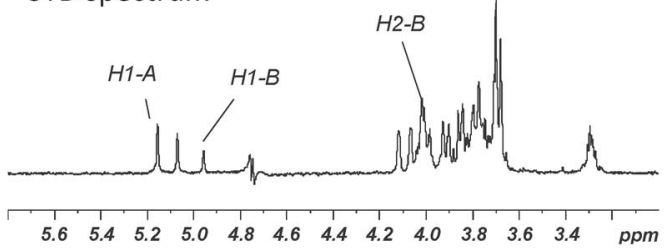

B

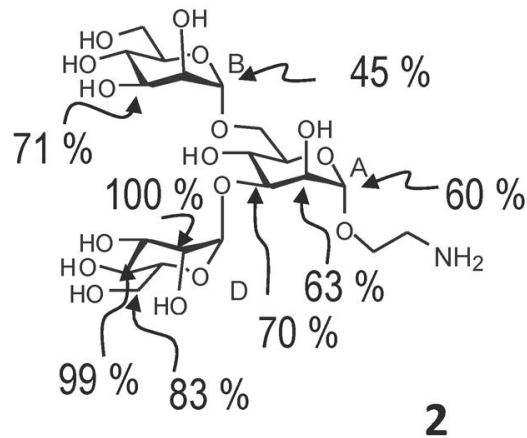

D
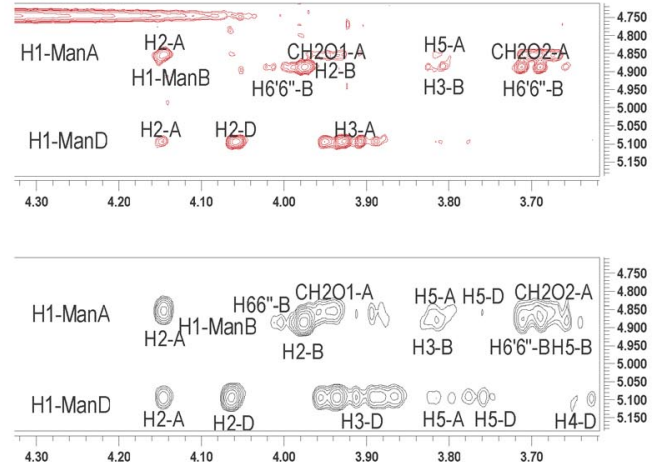

$E$
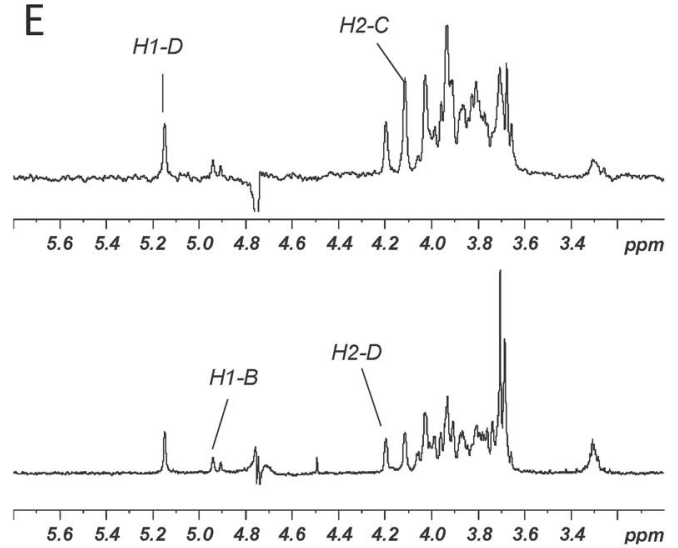

Reference spectrum

Fig. 1 Trisaccharide 1 (A) and 2 (B) with the relative STD values $(2 \mathrm{~s})$, (C and D, top) NOESY of the free trisaccharide registered at $500 \mathrm{MHz}$ in $150 \mathrm{mM} \mathrm{NaCl}, 20 \mathrm{mM}$ TRIS- $d_{6}, 4 \mathrm{mM} \mathrm{CaCl}_{2}$ at $278 \mathrm{~K}$ using a mixing time of $600 \mathrm{~ms}$, (C and D, bottom) transfer NOESY in the same conditions in the presence of 1:50 molar ratio of CD-SIGN EDC, (E and F) STD experiments at $2.5 \mathrm{~s}$ of saturation time in the same buffer as (C) and (D) for $\mathbf{1}$ and 2 , respectively. 


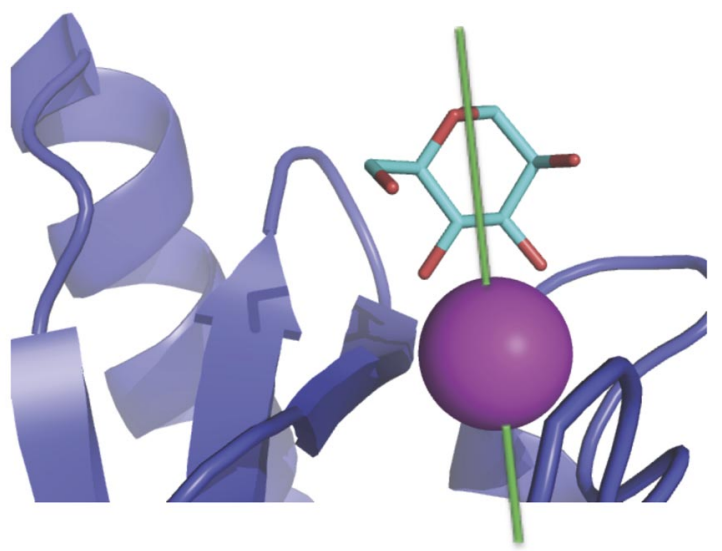

Fig. 2 CRD DC-SIGN complex with an oligomannoside (pdb code: 2it5) showing the interaction of the terminal mannose with the $\mathrm{Ca}^{2+}$ atom [41].

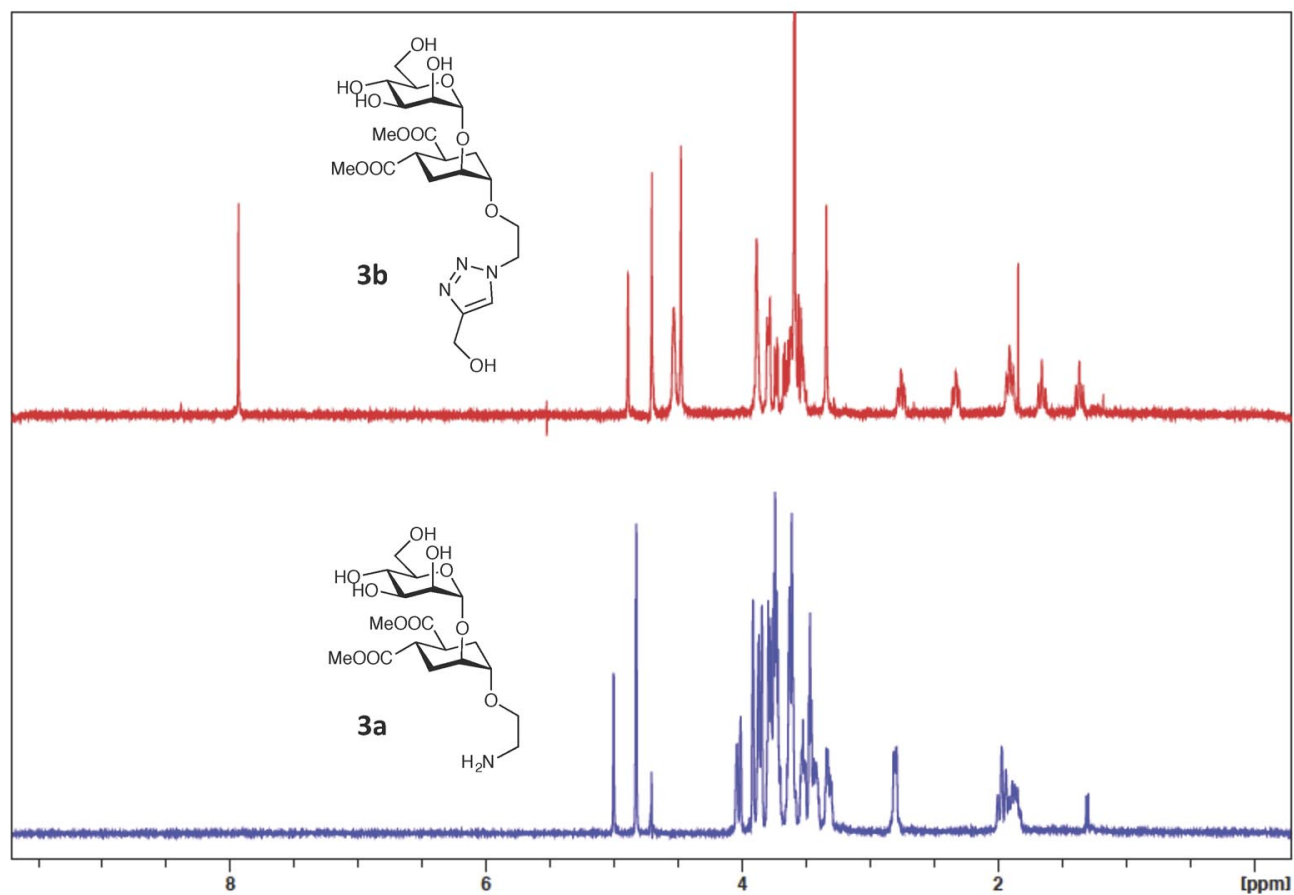

Fig. $3{ }^{1} \mathrm{H}$ NMR spectra of $\mathbf{3 a}$ and $\mathbf{3 b}$, notice the dispersion induced by the triazole moiety attached to the amino group of the linker.

Comparing the NOESY of $\mathbf{3 b}$ and the transfer NOESY in the presence of DC-SIGN (Fig. 4), both show essentially the same NOE cross-peaks pattern but with the opposite sign, indicating the presence of binding (see interglycosidic NOE sort distances labeled in Fig. 4B and corresponding cross-peaks in Figs $4 \mathrm{C}$ and $4 \mathrm{D}$ ). As the differences in the peak intensities can be attributed to the larger correlation time of the complex, this result is compatible with comparable conformations in both, the free and the bound ligand. 

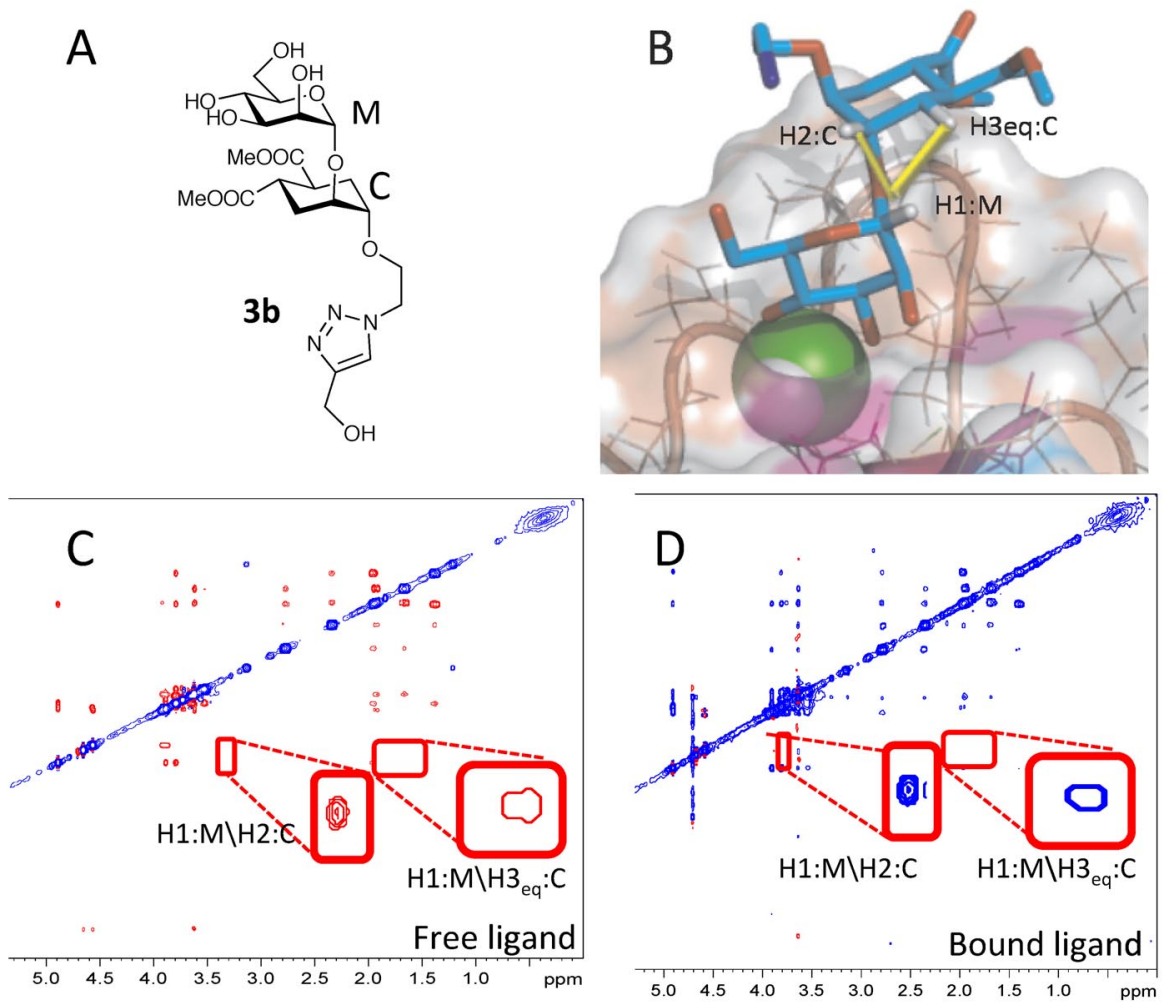

Fig. 4 (A) Pseudo-disaccharides 3a and 3b, (B) crystallographic structure of the complex between 3a and DC-SIGN CRD (pdb:2xr5), in dotted lines the NOE distances observed in the (C) NOESY of the free $3 \mathbf{b}$ and (D) transfer NOESY of $\mathbf{3 b}$ in the presence of DC-SIGN using a mixing time of $200 \mathrm{~ms}$, in the presence of $150 \mathrm{mM}$ $\mathrm{NaCl}, 20 \mathrm{mM}$ TRIS- $d_{6}, 4 \mathrm{mM} \mathrm{CaCl}_{2}$ at $278 \mathrm{~K}$ and both registered at $500 \mathrm{MHz}$.

The crystallographic structure shown in Fig. 5A was used to calculate the theoretical STD values (C) that were compared with the experimental ones (B). The agreement with the experimental ones (B) is remarkable (see Fig. 5), explaining the high value of the initial growing rate of proton 6ax due to its proximity to Val 351 .

An additional mimic, a pseudo-trisaccharide, was prepared by introducing an extra mannose residue in the reducing end of the carbohydrate, 4 (Fig. 6). The effects on the chemical shift dispersion induced by the triazole were smaller than those found for $\mathbf{4 b}$. As both compounds interact with DC-SIGN with additional strength, they were subject to NMR analysis, and transfer NOE and STD NMR experiments were performed.

Most of the intense STD signals were justified by the model structure (Fig. 6C) that resembles the interaction mode of the pseudo-disaccharide $4 \mathbf{b}$. However, in this case some STD signals for the reducing end mannose were observed in spite of the longer distance from the recognition site. Attempts to fit to multiple conformations based on variations of the 1-6 linkage geometry were unsuccessful. Finally, the introduction of a new complex that interacts with the $\mathrm{Ca}^{2+}$ via the opposite mannose, at the reducing end (see Fig. 6D), justifies the results shown in Fig. 6E for a mixture 80-20\%. 

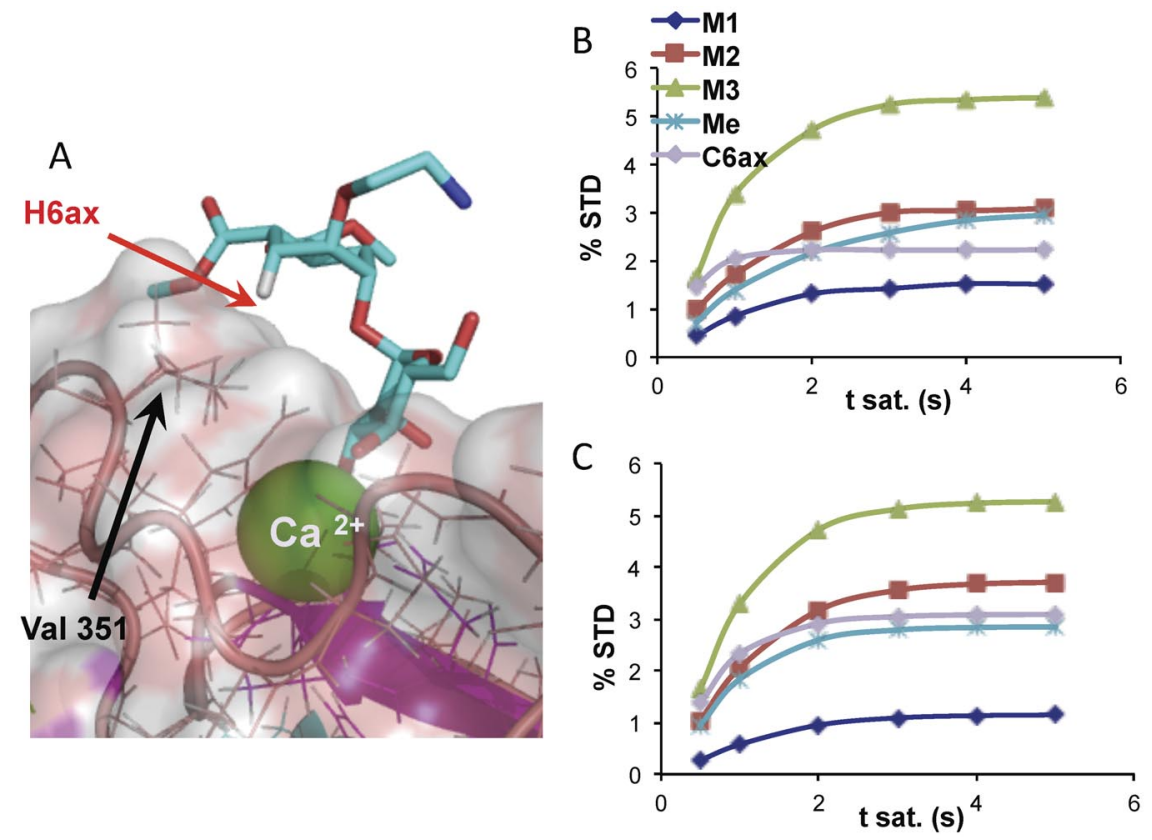

Fig. 5 (A) Crystallographic structure of the complex between 3a and DC-SIGN (pdb: 2xr5) showing the interactions with the calcium atom and between H6 from the carbohydrate and Val 351, (B) experimental, and (C) calculated using CORCEMA-ST, STD growing curves for the complex DC-SIGN EDC and 3a. Experimental conditions were $500 \mathrm{MHz}, 150 \mathrm{mM} \mathrm{NaCl}, 20 \mathrm{mM}$ TRIS- $d_{6}, 4 \mathrm{mM} \mathrm{CaCl}_{2}$ at $278 \mathrm{~K}$, and 1:50 molar ratio of DC-SIGN.

A
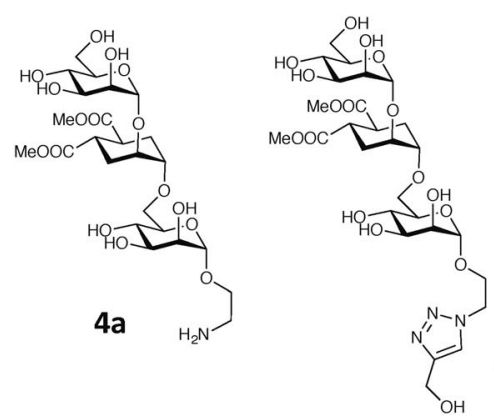

C

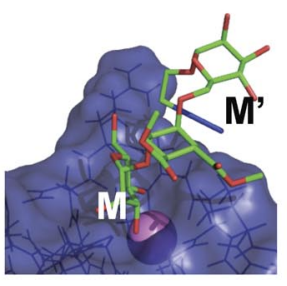

D

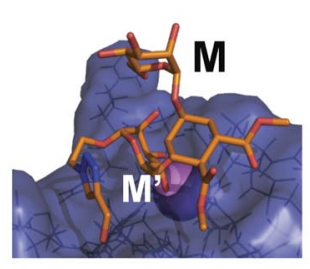

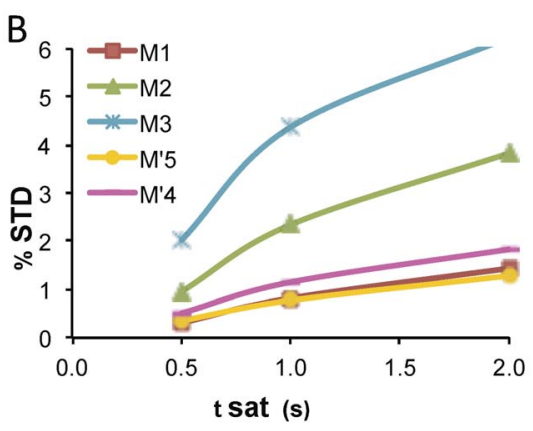

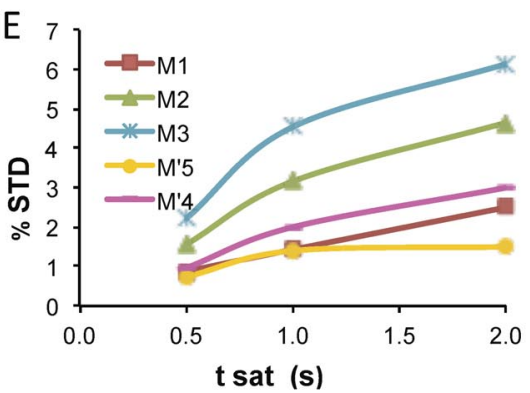

Fig. 6 (A) compound $4 \mathbf{b}$, (B) experimental STD growing curves for $4 \mathbf{b}$ in the presence of DC-SIGN ECD, 1:50 molar ratio, (C) X-ray model for trisaccharide $\mathbf{4 b}(\mathrm{pdb}: 2 \mathrm{xr} 6)$, (D) theoretical model corresponding to the inversion and rotation of the X-ray structure (notice that the mannose interacting with the calcium atom is the opposite from C), (E) theoretical STD growing curves corresponding to a mixture of conformations in proportions 80 to 20 (C to D). 


\section{Fucose-containing derivatives}

Besides mannose-containing oligosaccharides, many of the natural ligands of DC-SIGN are also oligosaccharides that contain fucose. Binding of fucose derivatives by DC-SIGN, mainly Lewis-type antigen determinants, has been reported by several groups [44-46]. Fucose itself was reported to bind DC-SIGN with dissociation constant about $6 \mathrm{mM}$ [47]. In order to get insight into their binding properties and modes, we have studied some fucose-containing compounds. The study started using a synthetic analogue of LeX, LeXOMe (5). The STD experiment reveals the interaction occurs mainly by the fucose residue (Fig. 7) [48]. A mimetic of LeX was synthesized, preserving the fucose moiety but replacing the glucosamine ring that has been substituted by a cyclohexyl ring and the galactose by a mimetic based on a cyclohexane with one ester and one amide, 6 [49]. When the same experiment was performed on 6, we obtained STD signals only for the fucose signals with a relative intensity very related to that obtained for the LeXOMe [49]. Thus, we can assign the same binding mode to both compounds. The structures available from X-ray studies with fucose derivatives display a mode of interaction that implies the interaction of the fucose ring with the $\mathrm{Ca}^{2+}$ atom, which in this case occurs mainly via hydroxyls in positions 3 and 4 that are in a cis-axial-equatorial disposition and not trans-diequatorial as in the case of mannose (Fig. 8) [50].

Using this information, a new series of fucose mimics with better affinity was designed and synthesized [22], among them $\mathbf{7}$ and $\mathbf{8}$ were selected for NMR studies. The structure was motivated by the structure of $\mathbf{6}$, replacing the terminal cyclohexyl ring by an aromatic moiety in order to improve the stability of the complexes by establishing new interactions $(\mathrm{CH}-\pi$ or $\pi-\pi)$ with either Val 351 or Phe 313 , which are in the proximities. After a conformational study of 7 (see Fig. 9 for the minimum energy conformer) the structural analysis of the respective complexes with DC-SIGN (EDC) was performed [48]. One of the main conclusions from this analysis is that, although the fucose ring still has the largest relative $S T D$ for the anomeric proton of the fucose, in both compounds the saturation is also transferred to

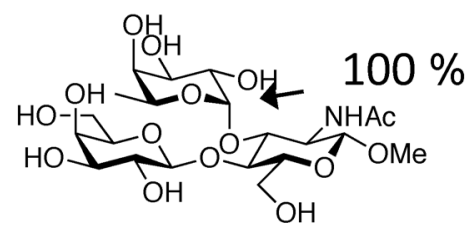

5

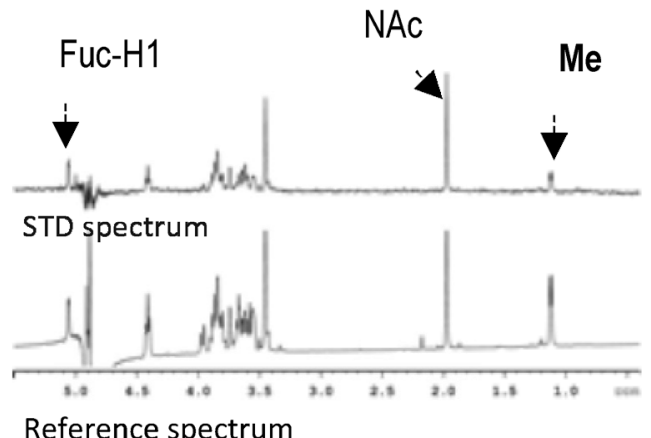

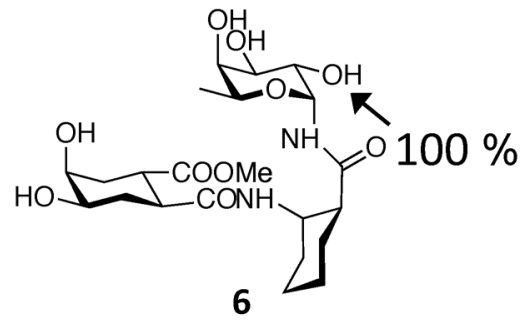

Fuc-H1 Fuc-H3

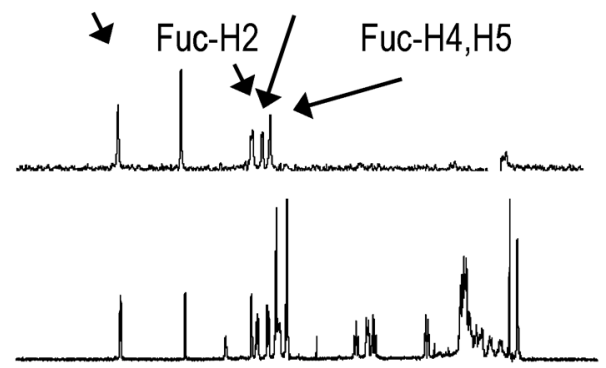

Fig. 7 Structures of $\mathrm{Le}^{\mathrm{X}} \mathrm{OMe}$ and mimetic 6 and STD experiments registered at 500 and $600 \mathrm{MHz}$, respectively, in the presence of $150 \mathrm{mM} \mathrm{NaCl}, 20 \mathrm{mM}$ TRIS- $d_{6}, 4 \mathrm{mM} \mathrm{CaCl}_{2}$ at $278 \mathrm{~K}$ using a saturation time of $2 \mathrm{~s}$ and 1:50 molar ratio of DC-SIGN. 


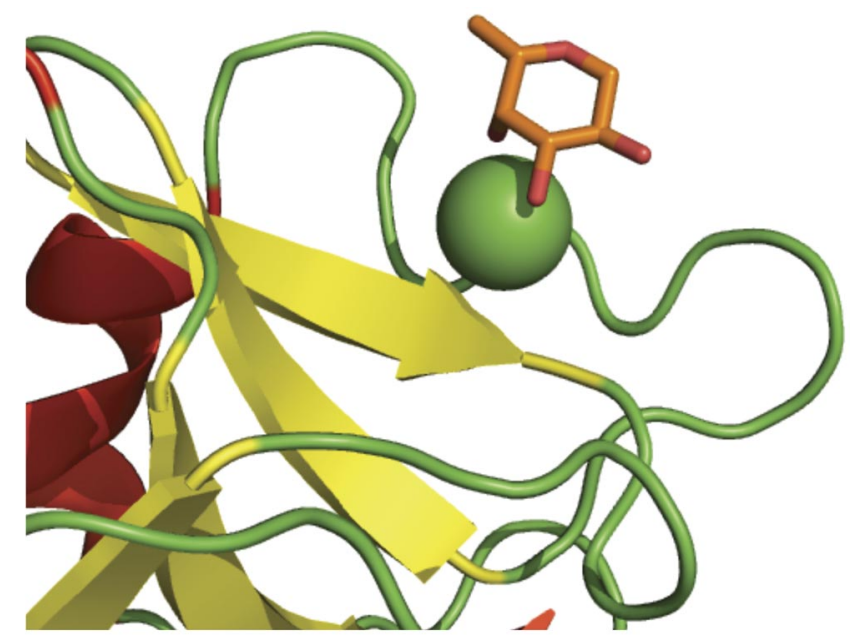

Fig. 8 1s15 crystallographic structure [50] showing the interaction between the $\mathrm{Ca}^{2+}$ atom and the fucose ring via $\mathrm{O} 3$ and $\mathrm{O} 4$.

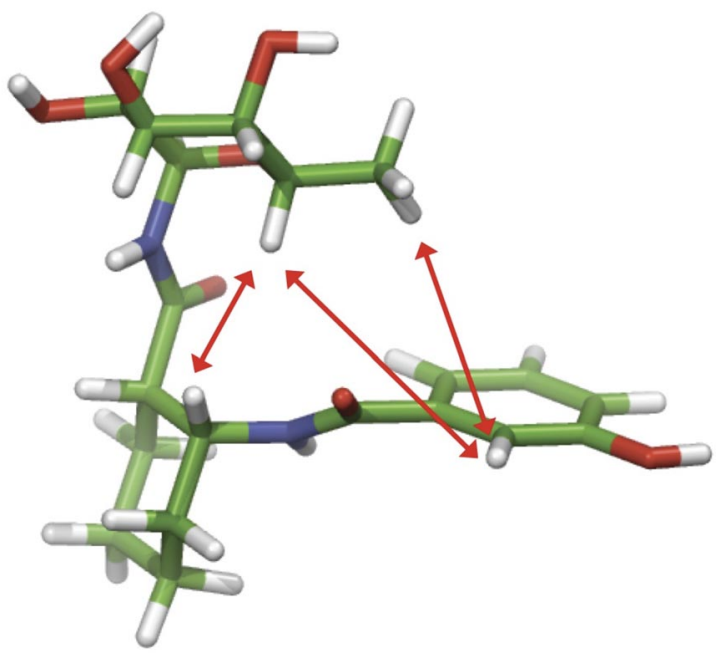

Fig. 9 Minimum energy conformation of compound 7 showing the diagnostic NOE observed.

the aromatic ring, indicating the participation of those in the binding to DC-SIGN (Fig. 6) [48]. Nevertheless, the influence of the electronic density on the ring or the possibility of acting as hydrogen bond donor or acceptor seems to not have a particular impact on the structure of the complex as both compounds display similar epitope maps and very similar relative $S T D$ values.

\section{STD in competition experiments}

The ability of NMR to detect different signals from each individual nucleus makes it a powerful tool to perform competition experiments. We have performed STD NMR competition experiments in our system using the fucosyl amide $\mathbf{8}, \mathrm{Le}^{\mathrm{X}} \mathbf{5}$, and $\alpha$-methyl mannoside, which differ on the chemical shift of the anomeric signal (Fig. 10). In one case, we recorded the STD growing curves for $\mathbf{8}$, while monitoring the anomeric proton. After we added $\mathrm{Le}^{\mathrm{X}}$ or mannoside, the same amount $(1 \mathrm{mM})$, recording the 


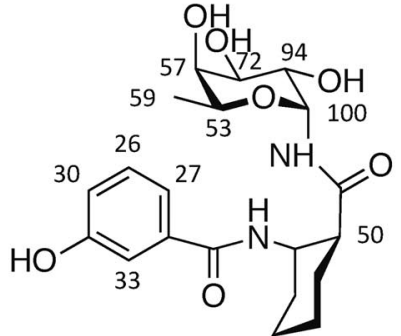

7

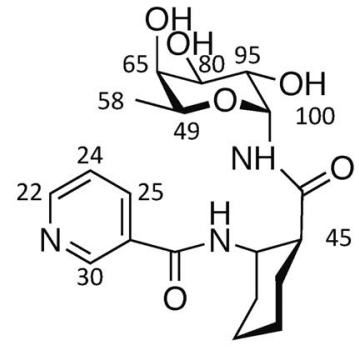

8
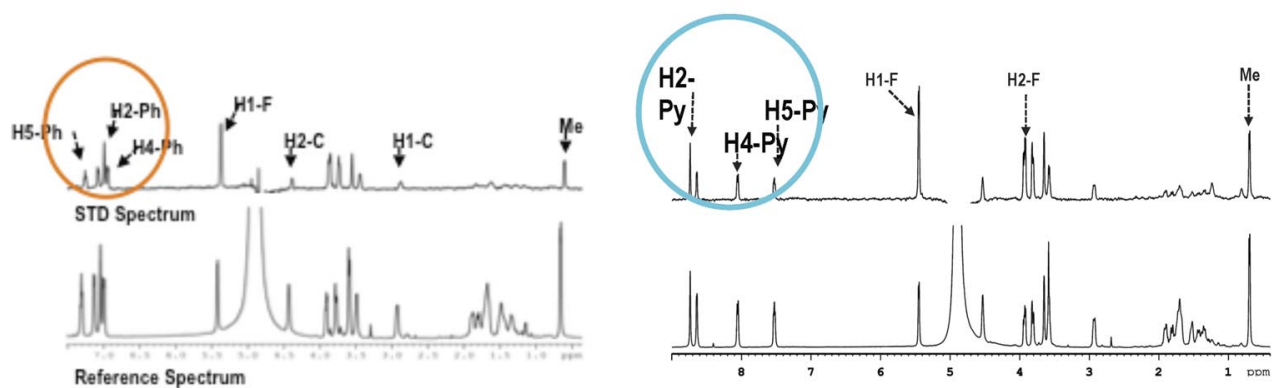

Fig. 10 Structures of $\mathrm{Le}^{\mathrm{X}}$ mimetics 7 (left) and $\mathbf{8}$ (right) showing the relative $S T D_{0}$ values (see below for further explanation) and STD experiments registered at $500 \mathrm{MHz}$, in the presence of $150 \mathrm{mM} \mathrm{NaCl}, 20 \mathrm{mM} \mathrm{TRIS}-d_{6}$, $4 \mathrm{mM} \mathrm{CaCl}_{2}$ at $278 \mathrm{~K}$ using a saturation time of $2 \mathrm{~s}$ and 1:50 molar ratio of DC-SIGN.<smiles>CC(O)OC1CCCCC1NC(=O)C1CCCC1NC(=O)c1cccnc1</smiles>

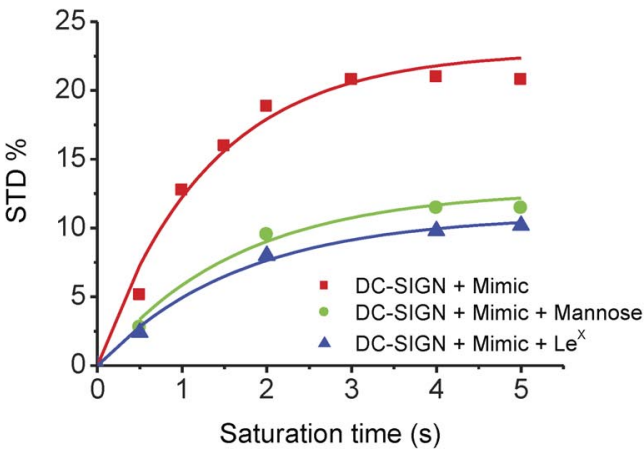

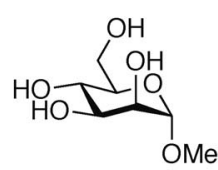
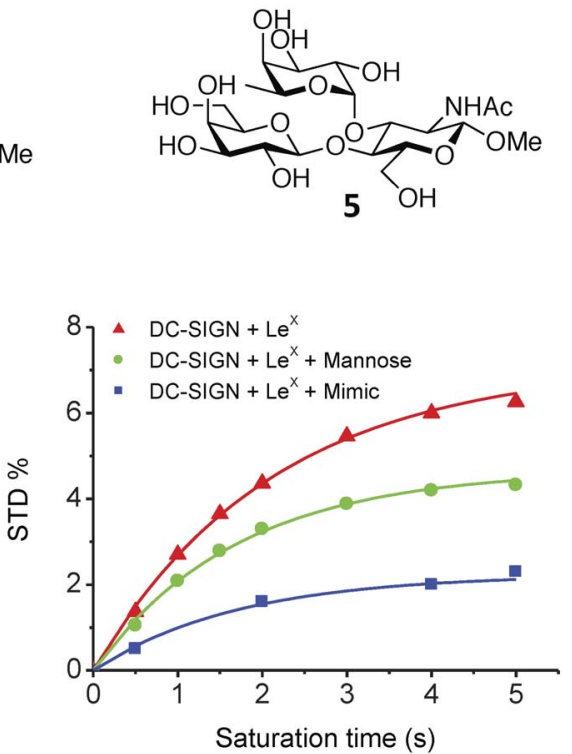

Fig. 11 Absolute $S T D$ growing curves (A) for the anomeric proton of $\mathbf{6}$ isolated (squares) for $\mathbf{6}$ and ManOMe (dots) and for $\mathbf{6}$ in the presence of equimolecular amount of $\mathbf{3}$ (triangles), and (B) for the anomeric proton of $\mathbf{3}$, alone (triangles), with ManOMe (dots) and in the presence of Le ${ }^{\mathrm{X}} \mathbf{6}$ (squares). Experimental conditions were the same as in Fig. 9. 
respective growing curves monitoring the anomeric proton of $\mathbf{8}$ (Fig. 11). In the other case, we registered three STD growing curves on a sample with $1 \mathrm{mM}$ of $\mathbf{5}$ alone, and in the presence of $1 \mathrm{mM}$ of mannose or the same concentration of mimic $\mathbf{8}$, while measuring the saturation transfer to the anomeric proton of Le ${ }^{\mathrm{X}}$ (see Fig. 11).

In both cases, Lewis ${ }^{\mathrm{X}}, \mathbf{5}$, and mimic $\mathbf{8}$, the $S T D$ signal for the anomeric proton decreases when ManOMe is added. This indicates that there is competitive binding for the same binding site. When the relative reduction of the signal was analyzed it could be concluded that the best binder corresponded to the fucosyl derivative $\mathbf{8}$, while $\mathrm{Le}^{\mathrm{X}}, \mathbf{5}$, and ManOMe have a similar binding constant (Fig. 11) [48].

Additional competition experiments between $\mathbf{7}$ and $\mathbf{8}$ were performed. STD experiments of a mixture of $\mathbf{7}$ and $\mathbf{8}$ were recorded, in the same tube, monitoring the anomeric signals of both compounds. They were chosen because they receive the major transfer of saturation (large STD), they belong to the common part of the molecules, and at the same time they had different chemical shifts. We have considered these signals instead of other more dispersed, e.g., the aromatic, as the results of the latter may be biased by the existence of different binding modes. The experiments were analyzed using the absolute $S T D$ in order to compensate the presence of a different amount of ligands (see Fig. 12). The analysis of the resulting growing curve with the mixing time is shown in Fig. 12, which corresponds to a similar $K_{\mathrm{D}}$ for both compounds [48].
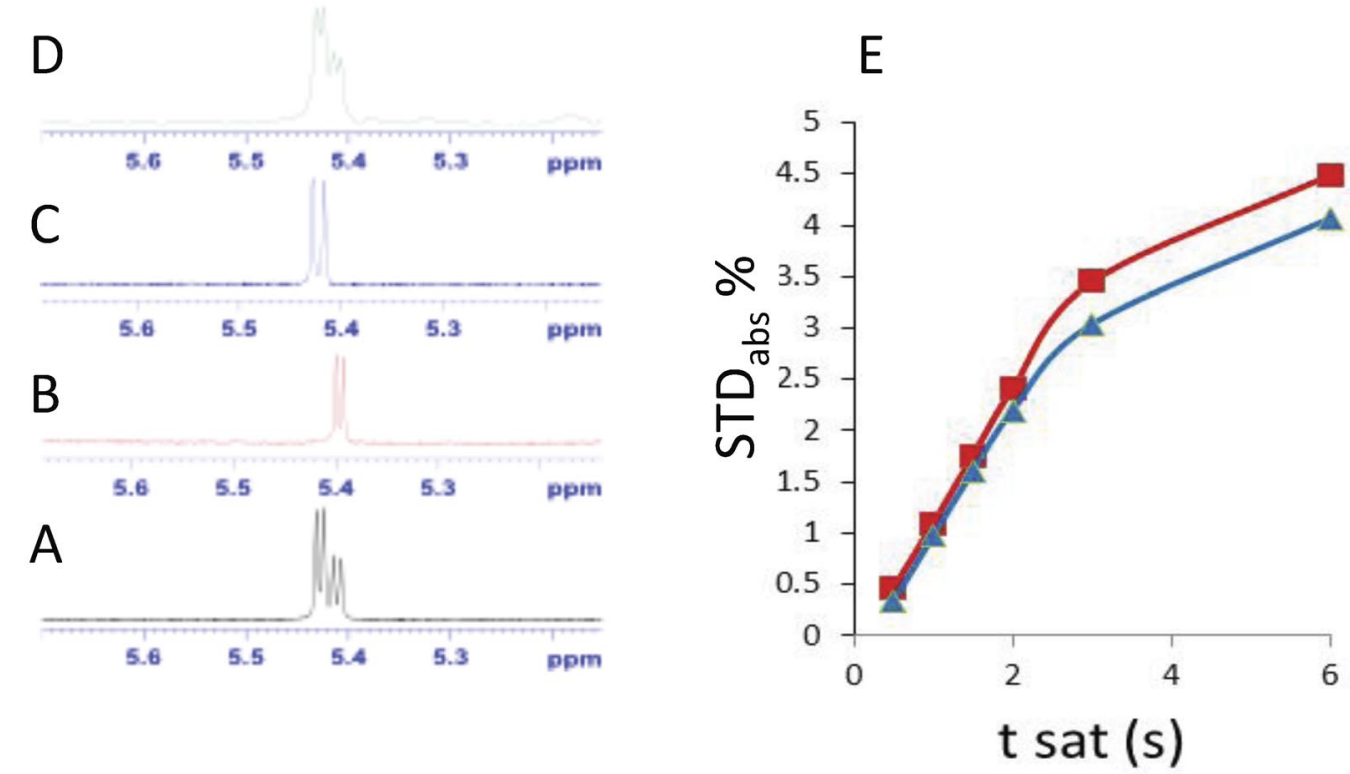

Fig. 12 Expansion of the anomeric region of the ${ }^{1} \mathrm{H}$ NMR of a mixture of 7 and 8 (A), 8 (B), 7 (C), and the STD NMR experiment (D) of the mixture represented in (A). Absolute STD growing curves of the mixture of $\mathbf{7}$ (squares) and $\mathbf{8}$ (triangles) evaluated at the respective anomeric signals (E). Experimental conditions were the same as in Fig. 9. The concentration of the pseudo-disaccharides was near to $1 \mathrm{mM}$ while the concentration of protein was $19 \mu \mathrm{M}$ in the habitual buffer.

\section{STD and $K_{\mathrm{D}}$}

From the first works on STD, the dependence of the STD intensity on the concentration of the ligandreceptor complex becomes evident. The intensity of the STD signals can be converted into a new magnitude proportional to the fraction of the bound ligand $(S T D-A F)$, resulting from the product between the observed STD and the molar excess of ligand over protein [30]. The evolution of the STD-AF as a 
function of the ligand concentration along a titration experiment should correspond to an association isotherm that could be fitted to a Langmuir-type equation

$$
f_{\mathrm{P}}=[\mathrm{L}] /\left(K_{\mathrm{D}}+[\mathrm{L}]\right)
$$

However, attempts to use this approach to extract binding constants have been unsuccessful due to additional dependences of the apparent $K_{\mathrm{D}}$ on other factors. This became evident when the values of the apparent $K_{\mathrm{D}}$ calculated from data obtained from several protons of the same ligand and obtained from the same experiments were different [51,52]. An alternative method was proposed to calculate binding constants relying on the calculation of the relative binding constant using the Cheng-Prusoff relationship [53]. This method, however, has the disadvantage of the need for an additional ligand of known $K_{\mathrm{D}}$ and compatibility with a competitive titration.

In a recent study, the impact of the experimental conditions (saturation time, receptor concentration, type of monitored proton...) on the value of the apparent $K_{\mathrm{D}}$ was evaluated [54]. From this work it could be concluded that the discrepancy between the real $K_{\mathrm{D}}$ and the apparent calculated from $S T D-A F$ was the pre-existing magnetization originating in previous binding events that lead to a lower capacity for receiving new magnetization from the ligand. This explains the deviation of the apparent $K_{\mathrm{D}}$ from the experimental saturation time, the dependence on the monitored signal, or the influence on the receptor concentrations (see Fig. 13) [54].

\section{BSA + Triptophan}

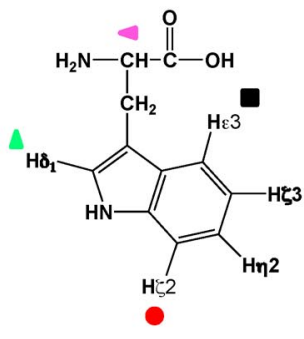

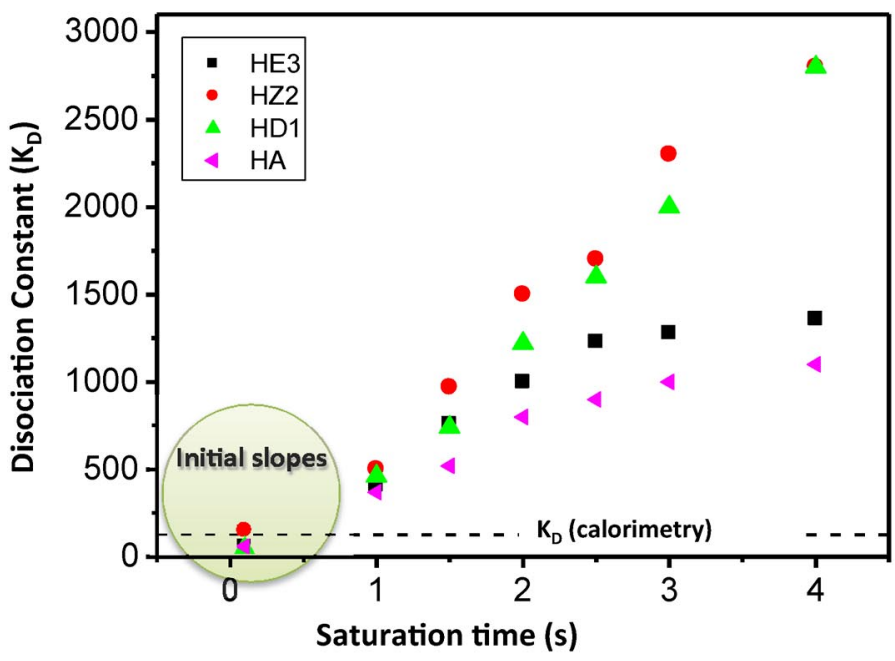

Fig. 13. Effect of the experimental factors (saturation time and monitored proton) on the determination of the apparent binding constant for the BSA — L-tryptophan system on a sample of $20 \mu \mathrm{m}$ of BSA.

From these results a new procedure for calculating binding constants from STD-NMR was developed [54]. This procedure was based on the use of the STD initial growth rates, $S T D_{0}$, calculated from STD growth curves, to construct the binding isotherm, instead of using the STD values obtained at given conditions. The rest of the treatment of the data was the same as that described for the apparent binding constants, and the results obtained were close to the $K_{\mathrm{D}}$ obtained by calorimetry. We have applied this method to real examples with good results [48,55].

\section{Theoretical evaluation of STD effects: CORCEMA-ST}

The quantitative analysis of an STD experiment of a given complex can be predicted using CORCEMAST (complete relaxation and conformational exchange matrix approach for STD NMR) [56,57], pro- 
vided a tentative structure for the free ligand, the complex, and other thermodynamics parameters: kinetics of association and dissociation, binding affinity, and NMR parameters: relaxation times, internal motions, order parameters, correlation times, etc. ... The predicted results are compared with the experimental ones validating or rejecting the model used for the calculations and yielding a 3D structure of the complex [58,59]. Further refinement could be done using a subsequent version of CORCEMA-ST, implementing SICO (STD NMR intensity restrained CORCEMA optimization) protocol [60-63]. This version uses a hybrid refinement protocol involving CORCEMA calculations and simulated annealing to refine the bound conformation from a structure previously docked into the binding pocket [57]. Some examples where the structures of the complex are calculated from STD data have been published recently using this methodology [55,64-66].

\section{Multiple binding modes into the same binding site}

In the crystallographic structure of mannose $\alpha(1-2)$ mannose with DC-SIGN CRD (pdb: 2it6) two alternative binding modes within the same binding site are shown. They differ only in the orientation, reducing end to non-reducing end, or vice versa of the dissacharide [41]. Both alternative binding modes interact with the lectin through coordination of the same groups (hydroxyls 3 and 4 of one mannose residue) with the $\mathrm{Ca}^{2+}$ atom. In the minor mode, one of the residues was disordered and could not be observed, while the major mode was completely defined. Therefore, two alternative minor binding modes were possible as a function of which of the mannoses is interacting with the calcium atom, both complexes were constructed and minimized.

The situation of the system can be considered as a particular case of competitive multiple binding where the binding site was the same for both complexes, that is, only one mode at time is allowed. Therefore, the total saturation accumulated in an STD experiment would be the sum of the accumulated saturations for each binding mode. However, although the STD for each binding mode could be calculated individually, the effect of cross-rebinding, this is a molecule previously saturated in one mode, and not fully relaxed, is bound in another mode and further saturated mixing the saturation from both modes, which cannot be calculated.

We demonstrated that at zero saturation time, the STD values are free of effects of rebinding and therefore of cross-rebinding [67]. Then the global $S T D_{0}$ value can be calculated using eq. 2, assuming that the contributions for all the potential binding modes were individually estimated.

$$
\begin{aligned}
& S T D_{0}=I_{0}-I_{\exp } / I_{0}\left|t_{\text {sat }=0}=\sum\left(I_{0} / I_{\text {cal }}\right) / I_{0}\right| t_{\text {sat }=0}=\Sigma S T D_{0} \\
& S T D=S T D_{\text {max }}\left[1-\exp \left(-k_{\text {sat }} t_{\text {sat }}\right)\right]
\end{aligned}
$$

The experimental STD initial slopes were estimated by the initial slope of the curve obtained by fitting the experimental values to eq. 3 as previously described. The experimental results were evaluated by comparing the experimental initial slopes and the predicted by CORCEMA-ST using the major complex and two possible modes that fit with the partial crystallographic data (Fig. 14). As the magnitude of STD is strongly dependent on the dissociation constant, we have considered a range on the millimolar scale and calculate the NOE-R factor $[68,69]$ to evaluate the results [67].

The results for the monomodal species were indicative of a bad agreement of one of the alternative binding complexes $(\mathrm{m} 1)$ while poor for the other $(\mathrm{m} 2)$ minor and the major $(\mathrm{M})$. However, when bimodal situations $(\mathrm{M}+\mathrm{m} 2)$ were considered in a ratio $1: 3$, as seen in the crystal, significant reductions on the NOE- $R$ factor were obtained, indicating a better agreement with the experimental [67]. 

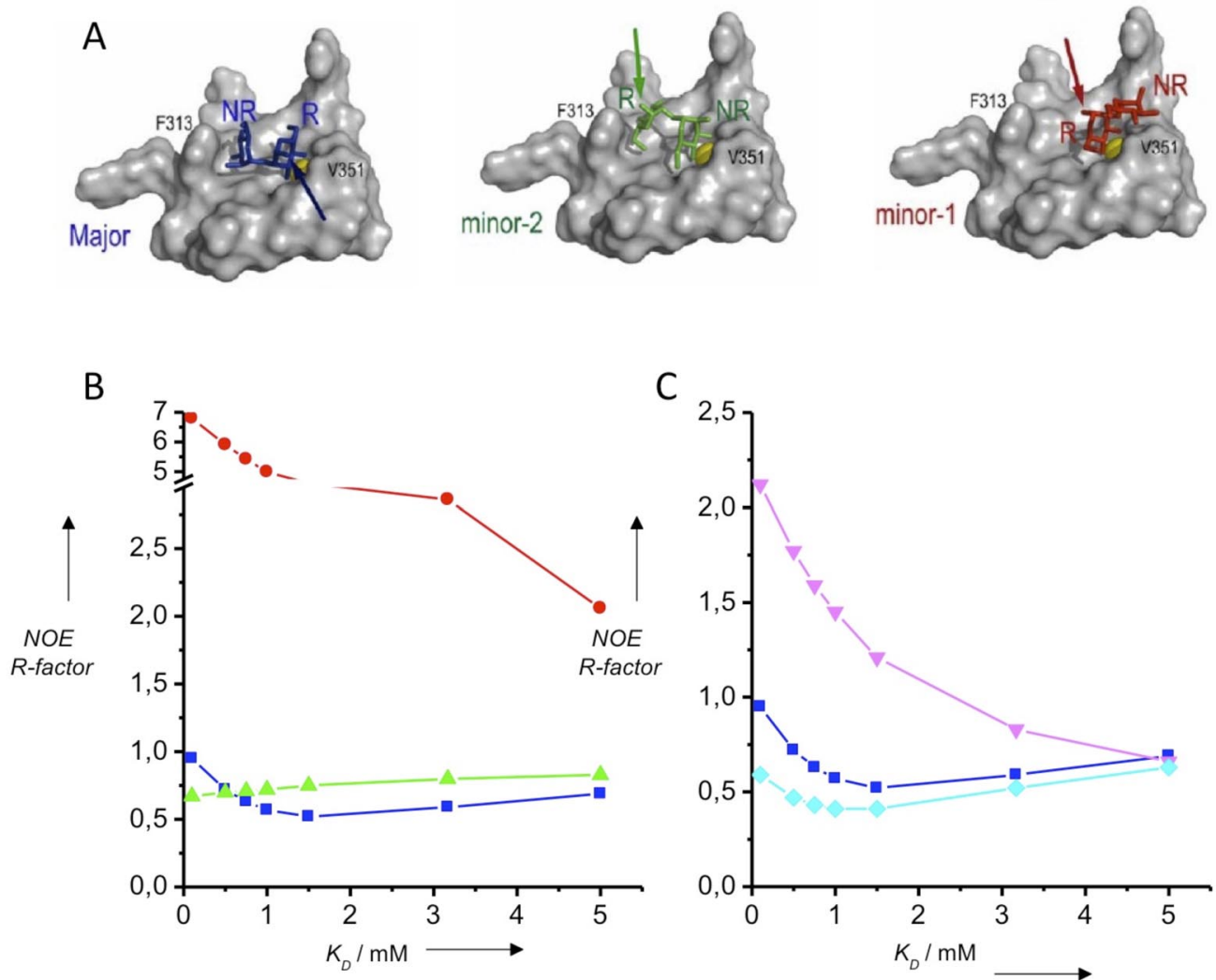

Fig. 14 (A) Partial structures of complexes. NOE R-factor as function of the binding constant for (B) monomodal complexes: major (squares), minor 1 (dots), minor 2 (triangles); and (C) bimodal complexes: major + minor 1 (triangles) and major + minor 2 (diamonds).

\section{CONCLUSIONS}

Although initially proposed for the analysis of binding of small ligand libraries, STD has been applied to a large number of systems and allows the extraction of rich structural binding information. The impetus of the STD application and the wide number of its applications can be attributed to the accessibility of the information about the geometry of the complex as epitope mapping, and contact between ligand and receptor. Providing a previous structure or a reasonable model calculated for the complex, a local structure of the complex could be obtained by fitting the predictions with the experimental results without the need of the use of labeled protein samples. The comparison of the experimental and theoretical $S T D-A F_{0}$ values can be used to deduce more precise geometrical information, even in the cases of multiple binding modes.

\section{ACKNOWLEDGMENTS}

Support of this work for funding by the EU (PITN-GA-2008-213592, CARMUSYS), MICINN (CTQ2009-07168) and (CTQ2008-01694), and MEC (ITCS-2009-43 for access to $800 \mathrm{MHz}$ on LRB) are gratefully acknowledged. We also thank the European FEDER funds. J. A., J. C. M.-G., and C. G. acknowledge MICINN for a Ramón y Cajal contract, CSIC for a JAE fellowship, and the EU for a Marie Curie Fellowship, respectively. We are grateful to the participants on the CARMUSYS network for providing compounds and fruitful suggestions. 


\section{REFERENCES}

1. J. Banchereau, R. M. Steinman. Nature 392, 245 (1998).

2. D. Bell, J. W. Young, J. Banchereau. Adv. Immunol. 72, 255 (1999).

3. Y. van Kooyk, A. Engering, A. N. Lekkerkerker, I. S. Ludwig, T. B. Geijtenbeek. Curr. Opin. Immunol. 16, 488 (2004).

4. T. B. H. Geijtenbeek, R. Torensma, S. J. van Vliet, G. C. F. van Duijnhoven, G. J. Adema, Y. van Kooyk, C. G. Figdor. Cell 100, 575 (2000).

5. Y. van Kooyk, T. B. H. Geijtenbeek. Nat. Rev. Immunol. 3, 697 (2003).

6. T. B. H. Geijtenbeek, Y. van Kooyk. Apmis 111, 698 (2003).

7. A. Hodges, K. Sharrocks, M. Edelmann, D. Baban, A. Moris, O. Schwartz, H. Drakesmith, K. Davies, B. Kessler, A. McMichael, A. Simmons. Nat. Immunol. 8, 569 (2007).

8. G. Tabarani, M. Thepaut, D. Stroebel, C. Ebel, C. Vives, P. Vachette, D. Durand, F. Fieschi. J. Biol. Chem. 284, 21229 (2009).

9. G. Tabarani, J. J. Reina, C. Ebel, C. Vives, H. Lortat-Jacob, J. Rojo, F. Fieschi. FEBS Lett. 580, 2402 (2006).

10. O. Martinez-Avila, K. Hijazi, M. Marradi, C. Clavel, C. Campion, C. Kelly, S. Penades. Chem.Eur. J. 15, 9874 (2009).

11. C. R. Becer, M. I. Gibson, J. Geng, R. Ilyas, R. Wallis, D. A. Mitchell, D. M. Haddleton. J. Am. Chem. Soc. 132, 15130 (2010).

12. M. Ciobanu, K.-T. Huang, J.-P. Daguer, S. Barluenga, O. Chaloin, E. Schaeffer, C. G. Mueller, D. A. Mitchell, N. Winssinger. Chem. Commun. 47, 9321 (2011).

13. A. Cambi, F. de Lange, N. M. van Maarseveen, M. Nijhuis, B. Joosten, E. van Dijk, B. I. de Bakker, J. A. M. Fransen, P. H. M. Bovee-Geurts, F. N. van Leeuwen, N. F. Van Hulst, C. G. Figdor. J. Cell Biol. 164, 145 (2004).

14. B. I. de Bakker, F. de lange, A. Cambi, J. P. Korterik, E. M. H. P. van Dijk, N. F. van Hulst, C. G. Figdor, M. F. Garcia-Parajo. ChemPhysChem 8, 1473 (2007).

15. O. Martinez-Avila, L. M. Bedoya, M. Marradi, C. Clavel, J. Alcami, S. Penades. ChemBioChem 10, 1806 (2009).

16. S. Sattin, A. Daghetti, M. Thepaut, A. Berzi, M. Sanchez-Navarro, G. Tabarani, J. Rojo, F. Fieschi, M. Clerici, A. Bernardi. ACS Chem. Biol. 5, 301 (2010).

17. S.-K. Wang, P.-H. Liang, R. D. Astronomo, T.-L. Hsu, S.-L. Hsieh, D. R. Burton, C.-H. Wong. Proc. Natl. Acad. Sci. USA 105, 3690 (2008).

18. J. Luczkowiak, S. Sattin, I. Sutkeviciute, J. Juan Reina, M. Sanchez-Navarro, M. Thepaut, L. Martinez-Prats, A. Daghetti, F. Fieschi, R. Delgado, A. Bernardi, J. Rojo. Bioconjugate Chem. 22, 1354 (2011).

19. J. J. Reina, S. Sattin, D. Invernizzi, S. Mari, L. Martinez-Prats, G. Tabarani, F. Fieschi, R. Delgado, P. M. Nieto, J. Rojo, A. Bernardi. ChemMedChem 2, 1030 (2007).

20. D. A. Mitchell, N. A. Jones, S. J. Hunter, J. M. D. Cook, S. F. Jenkinson, M. R. Wormald, R. A. Dwek, G. W. J. Fleet. Tetrahedron: Asymmetry 18, 1502 (2007).

21. K. C. A. Garber, K. Wangkanont, E. E. Carlson, L. L. Kiessling. Chem. Commun. 46, 6747 (2010).

22. M. Andreini, D. Doknic, I. Sutkeviciute, J. J. Reina, J. Duan, E. Chabrol, M. Thepaut, E. Moroni, F. Doro, L. Belvisi, J. Weiser, J. Rojo, F. Fieschi, A. Bernardi. Org. Biomol. Chem. 9, 5778 (2011).

23. S. Forsen, R. A. Hoffman. J. Chem. Phys. 39, 2892 (1963).

24. E. I. Hyde, B. Birdsall, G. C. K. Roberts, J. Feeney, A. S. V. Burgen. Biochemistry 19, 3738 (1980).

25. M. Mayer, B. Meyer. Angew. Chem., Int. Ed. 38, 1784 (1999).

26. B. Meyer, T. Peters. Angew. Chem., Int. Ed. 42, 864 (2003). 
27. C. A. Lepre, J. M. Moore, J. W. Peng. Chem. Rev. 104, 3641 (2004).

28. M. Pellecchia, I. Bertini, D. Cowburn, C. Dalvit, E. Giralt, W. Jahnke, T. L. James, S. W. Homans, H. Kessler, C. Luchinat, B. Meyer, H. Oschkinat, J. Peng, H. Schwalbe, G. Siegal. Nat. Rev. Drug Discovery 7, 738 (2008).

29. M. Pellecchia, D. S. Sem, K. Wuthrich. Nat. Rev. Drug Discovery 1, 211 (2002).

30. M. Mayer, B. Meyer. J. Am. Chem. Soc. 123, 6108 (2001).

31. M. Vogtherr, T. Peters. J. Am. Chem. Soc. 122, 6093 (2000).

32. T. Diercks, J. P. Ribeiro, F. J. Cañada, S. André, J. Jiménez-Barbero, H.-J. Gabius. Chem.-Eur. J. 15, 5666 (2009).

33. C. Rauber, S. Berger. Magn. Reson. Chem. 48, 91 (2010).

34. M. Mayer, T. L. James. J. Am. Chem. Soc. 126, 4453 (2004).

35. D. D. Ho, J. C. Kaplan, I. E. Rackauskas, M. E. Gurney. Science 239, 1021 (1988).

36. H. Feinberg, D. A. Mitchell, K. Drickamer, W. I. Weis. Science 294, 2163 (2001).

37. J. J. Reina, I. Diaz, P. M. Nieto, N. E. Campillo, J. A. Paez, G. Tabarani, F. Fieschi, J. Rojo. Org. Biomol. Chem. 6, 2743 (2008).

38. A. A. Bothner-By, J. H. Noggle. J. Am. Chem. Soc. 101, 5152 (1979).

39. J. P. Albrand, B. Birdsall, J. Feeney, G. C. K. Roberts, A. S. V. Burgen. Int. J. Biol. Macromol. 1, 37 (1979).

40. F. Ni. Prog. Nucl. Magn. Reson. Spectrosc. 26, 517 (1994).

41. H. Feinberg, R. Castelli, K. Drickamer, P. H. Seeberger, W. I. Weis. J. Biol. Chem. 282, 4202 (2007).

42. M. Sanchez-Navarro, J. Rojo. Drug News Perspect. 23, 557 (2010).

43. M. Thépaut, C. Guzzi, I. Sutkeviciute, S. Sattin, R. Ribeiro-Viana, N. Varga, E. Chabrol, J. Rojo, A. Bernardi, J. Angulo, P. M. Nieto, F. Fieschi. J. Am. Chem. Soc. 135, 2518 (2013).

44. B. J. Appelmelk, I. van Die, S. J. van Vliet, C. Vandenbroucke-Grauls, T. B. H. Geijtenbeek, Y. van Kooyk. J. Immunol. 170, 1635 (2003).

45. D. A. Mitchell, A. J. Fadden, K. Drickamer. J. Biol. Chem. 276, 28939 (2001).

46. S. Meyer, E. van Liempt, A. Imberty, Y. van Kooyk, H. Geyer, R. Geyer, I. van Die. J. Biol. Chem. 280, 37349 (2005).

47. E. P. Mitchell, C. Sabin, L. Snajdrova, M. Pokorna, S. Perret, C. Gautier, C. Hofr, N. GilboaGarber, J. Koca, M. Wimmerova, A. Imberty. Proteins: Struct. Funct. Bioinf. 58, 735 (2005).

48. C. Guzzi, J. Angulo, F. Doro, J. J. Reina, M. Thepaut, F. Fieschi, A. Bernardi, J. Rojo, P. M. Nieto. Org. Biomol. Chem. 9, 7705 (2011).

49. G. Timpano, G. Tabarani, M. Anderluh, D. Invernizzi, F. Vasile, D. Potenza, P. M. Nieto, J. Rojo, F. Fieschi, A. Bernardi. ChemBioChem 9, 1921 (2008).

50. Y. Guo, H. Feinberg, E. Conroy, D. A. Mitchell, R. Alvarez, O. Blixt, M. E. Taylor, W. I. Weis, K. Drickamer. Nat. Struct. Mol. Biol. 11, 591 (2004).

51. A. T. Neffe, M. Bilang, I. Gruneberg, B. Meyer. J. Med. Chem. 50, 3482 (2007).

52. M. Pickhardt, G. Larbig, I. Khlistunova, A. Coksezen, B. Meyer, E. M. Mandelkow, B. Schmidt, E. Mandelkow. Biochemistry 46, 10016 (2007).

53. Y. Cheng, W. H. Prusoff. Biochem. Pharmacol. 22, 3099 (1973).

54. J. Angulo, P. M. Enriquez-Navas, P. M. Nieto. Chem.—Eur. J. 16, 7803 (2010).

55. P. M. Enríquez-Navas, M. Marradi, D. Padro, J. Angulo, S. Penadés. Chem.-Eur. J. 17, 1547 (2011).

56. V. Jayalakshmi, N. R. Krishna. J. Magn. Reson. 155, 106 (2002).

57. N. Rama Krishna, V. Jayalakshmi. Prog. Nucl. Magn. Reson. Spectrosc. 49, 1 (2006).

58. A. Bhunia, V. Jayalakshmi, A. J. Benie, O. Schuster, S. Kelm, N. R. Krishna, T. Peters. Carbohydr. Res. 339, 259 (2004).

59. J. Angulo, B. Langpap, A. Blume, T. Biet, B. Meyer, N. R. Krishna, H. Peters, M. M. Palcic, T. Peters. J. Am. Chem. Soc. 128, 13529 (2006). 
60. V. Jayalakshmi, T. Biet, T. Peters, N. R. Krishna. J. Am. Chem. Soc. 126, 8610 (2004).

61. V. Jayalakshmi, N. R. Krishna. J. Magn. Reson. 168, 36 (2004).

62. V. Jayalakshmi, T. Biet, T. Peters, N. R. Krishna. J. Am. Chem. Soc. 127, 7261 (2005).

63. V. Jayalakshmi, N. R. Krishna. J. Am. Chem. Soc. 127, 14080 (2005).

64. A. Canales, J. Rodriguez-Salarichs, C. Trigili, L. Nieto, C. Coderch, J. M. Andreu, I. Paterson, J. Jimenez-Barbero, J. F. Diaz. ACS Chem. Biol. 6, 789 (2011).

65. M. G. Szczepina, D. W. Bleile, B. M. Pinto. Chem.-Eur. J. 17, 11446 (2011).

66. Y. Yuan, D. W. Bleile, X. Wen, D. A. R. Sanders, K. Itoh, H. W. Liu, B. M. Pinto. J. Am. Chem. Soc. 130, 3157 (2008).

67. J. Angulo, I. Diaz, J. J. Reina, G. Tabarani, F. Fieschi, J. Rojo, P. M. Nieto. ChemBioChem 9, 2225 (2008).

68. Y. Xu, I. P. Sugar, N. R. Krishna. J. Biomol. NMR 5, 37 (1995).

69. N. R. Krishna, D. G. Agresti, J. D. Glickson, R. Walter. Biophys. J. 24, 791 (1978). 